\title{
Entropy Spectral Analyses for Groundwater Forecasting
}

\author{
Huijaun Cui ${ }^{1}$ and Vijay P. Singh, Dist.M.ASCE ${ }^{2}$
}

\begin{abstract}
Forecasting of monthly and annual groundwater levels is important for water resources management, irrigation, and assessment of climate change. This study employs entropy spectral analysis for forecasting monthly groundwater levels. For spectral analysis, the domain of consideration for defining entropy is the frequency domain, in which three types of entropies are known: Burg entropy, configurational entropy, and relative entropy. These entropies lead to three types of spectral analysis: (1) Burg entropy spectral analysis (BESA), (2) configurational entropy spectral analysis (CESA), and (3) relative entropy spectral analysis (RESA). BESA, CESA, and RESA are employed to analyze spectra and forecast monthly groundwater levels, and then they are compared to determine which spectral analysis method better forecasts the monthly groundwater level. Monthly and annual groundwater data were obtained from South Carolina to verify the three methods. Both monthly and annual groundwater level data showed significant decreasing trends at almost all stations. It was found that relative entropy yielded the highest resolution in determining the spectral density, while for simulating groundwater levels, all three methods fitted the observed values well. This was indicated by the average value of Nash-Sutcliffe efficiency (NSE) for BESA, CESA, and RESA being 0.69, 0.70, and 0.70, respectively. DOI: 10.1061/(ASCE)HE.1943-5584.0001512. () 2017 American Society of Civil Engineers.
\end{abstract}

Author keywords: Entropy theory; Spectral analysis; Burg entropy; Relative entropy; Configurational entropy; Groundwater level.

\section{Introduction}

Although entropy theory has been widely applied in surface-water hydrology (Singh 1997, 2011; Singh et al. 2007), its application in groundwater hydrology is limited. Entropy can be defined either in the real domain or frequency domain. In the real domain, entropy theory allows a probabilistic description of a groundwater variable. The principle of maximum entropy (Jaynes 1957a, b) has been applied to estimate the groundwater head distribution (Barbe et al. 1994) and monitor groundwater quality (Mogheir et al. 2004, 2009, 2006). Woodbury and Ulrych $(1993,1996,1998)$ used the relative entropy theory for forward groundwater modeling and solving inverse problems. In the frequency domain, Burg entropy (BESA) (Burg 1967, 1975), configurational entropy (CESA) (Frieden 1972; Gull and Daniell 1978), and relative entropy (RESA) (Shore 1979, 1981; Tzannes et al. 1985), which connect the spectral analysis and time-series analysis, can be applied to time-series forecasting. These entropy methods not only improve the resolution of spectral density but also improve the reliability of time-series modeling (Liefhebber and Boekee 1987; Papademetriou 1998).

These entropies have been applied to streamflow time series (Cui and Singh 2015, 2016; Krstanovic and Singh 1991a, b; Singh and Cui 2015), but they have not yet been applied to groundwater time series. Because groundwater is stored deep under the land's

\footnotetext{
${ }^{1}$ Associate Professor, Key Laboratory of Land Surface Pattern and Simulation, Institute of Geographic Sciences and Natural Resources Research, Chinese Academy of Sciences, 11A Datun Rd., Chaoyang District, Beijing 100101, China (corresponding author). ORCID: http://orcid.org/ 0000-0002-0308-1550. E-mail: cuihj@igsnrr.ac.cn

${ }^{2}$ Distinguished Professor and Caroline and William N. Lehrer Distinguished Chair in Water Engineering, Dept. of Biological and Agricultural Engineering, Zachry Dept. of Civil Engineering, Texas A\&M Univ., 321 Scoates Hall, 2117 TAMU, College Station, TX 77843-2117. E-mail: vsingh@tamu.edu

Note. This manuscript was submitted on May 5, 2016; approved on December 7, 2016; published online on March 3, 2017. Discussion period open until August 3, 2017; separate discussions must be submitted for individual papers. This technical note is part of the Journal of Hydrologic Engineering, (C) ASCE, ISSN 1084-0699.
}

surface and is less disturbed by external environmental factors, its fluctuations are much lower than those of the surface streamflow. As a result, the groundwater time series do not share the same patterns as streamflow and neither do their spectra. It would therefore be interesting to investigate how spectral analysis would work for forecasting groundwater time series. The objective of this study therefore was to develop the three entropy-based spectral analyses for forecasting monthly and annual groundwater level data, determine groundwater level spectra, forecast groundwater levels, and determine which spectral analysis would perform better for forecasting monthly groundwater levels.

\section{Methods}

\section{Entropy in the Frequency Domain}

For forecasting groundwater, the temporal variation of groundwater needs to be investigated. To that end, the groundwater time series is first represented using spectra and then defining entropy in the frequency domain. Let frequency $f$ be regarded as a random variable, and let the normalized spectral density be denoted as $p(f)$. The three types of entropy are defined as follows.

Burg entropy can be defined as

$$
H_{B}(f)=-\int_{-W}^{W} \ln [p(f)] d f
$$

where $p=$ spectral density function, which can be taken as analogous to a probability density function; $f=$ frequency that varies from $-W$ to $W ; W=1 /(2 \Delta t)=$ Nyquist foldover frequency; and $\Delta t=$ sampling period, which was 1 month in this study.

The configurational entropy is defined by taking the expectation of the $\log$ of spectral density as

$$
H_{C}(f)=-\int_{-W}^{W} p(f) \ln [p(f)] d f
$$

If there is information on the spectral density of $f$, denoted by $q(f)$, often called prior spectral density, then the relative entropy of the spectral density $p(f)$ can be defined as 


$$
H_{R}(f)=\int p(f) \ln [p(f) / q(f)] d f
$$

The prior spectral density can be taken as a background noise with the peak assumed at the observed periodicity. When a uniform prior is taken, the relative entropy given by Eq. (3) reduces to the configurational entropy given by Eq. (2).

Entropy defined by the preceding three equations was used to quantify uncertainty associated with groundwater time series in that higher entropy would correspond to more uncertainty captured from groundwater variations. For the three types of entropies defined in the frequency domain, three types of spectral analysis were correspondingly obtained by maximizing the Burg entropy and configurational entropy while minimizing the relative entropy, subject to specified constraints.

\section{Specification of Constraints}

For a given groundwater level data series, the autocorrelations corresponding to different lags can be determined. Because there is a one-to-one relationship between autocorrelation and spectral density function, the constraints can be formed from this relationship. Using the first $N$ lags of autocorrelation, the constraints can be written as

$$
\rho_{n}=\int_{-W}^{W} p(f) e^{i 2 \pi f n \Delta t} d f, \quad-N \leq n \leq N
$$

where $i=\sqrt{-1}$; and $\rho_{n}=$ autocorrelation function of $n$th lag. When $n=0$, Eq. (4) reduces to

$$
\rho_{0}=\int_{-W}^{W} p(f) d f=1
$$

where $\rho_{0}=$ autocorrelation at the 0th lag.

\section{Maximization of Burg or Configurational Entropy or Minimization of Relative Entropy}

To obtain the least-biased estimation of the spectra, Burg entropy and configurational entropy need to be maximized or the relative entropy to be minimized with the use of Lagrange multipliers. Therefore, spectral densities were obtained as

$$
\begin{gathered}
p_{B}(f)=\frac{1}{\sum_{n=-N}^{N} \lambda_{n} e^{-i 2 \pi f n \Delta t}} \\
p_{C}(f)=\exp \left(-1-\sum_{n=-N}^{N} \lambda_{n} e^{i 2 \pi f n \Delta t}\right) \\
p_{R}(f)=q(f) \exp \left(-1-\sum_{n=-N}^{N} \lambda_{n} e^{i 2 \pi f n \Delta t}\right)
\end{gathered}
$$

It can be seen from Eqs. (6)-(8) that the spectral density derived from Burg entropy is in the form of inverse of polynomials, while the ones from the configurational entropy and relative entropy are in the exponential form.

\section{Determination of Lagrange Multipliers}

The methods for determining Lagrange multipliers are different for the different entropy-based spectral densities formulated earlier. For Burg entropy, Lagrange multipliers can be computed from the Levinson-Burg algorithm developed by Burg $(1967,1975)$. On the other hand, parameters of the configurational entropy and relative entropy approaches can be determined using the cepstrum analysis as discussed by Cui and Singh $(2015,2016)$, which is given as

$$
\begin{gathered}
\lambda_{0}=-1-e_{p}(0)+e_{q}(0) \\
\lambda_{1}=-e_{p}(1)+e_{q}(1) \\
\vdots \\
\lambda_{k}=-e_{p}(k)+e_{q}(k)
\end{gathered}
$$

\begin{tabular}{|c|c|c|c|c|c|}
\hline Name & Station number & Latitude N & Longitude W & $\begin{array}{c}\text { Depth of } \\
\text { well [m (ft)] }\end{array}$ & Aquifer \\
\hline Oconee County & 345051083041800 OC-233 & $34^{\circ} 50^{\prime} 51^{\prime \prime}$ & $83^{\circ} 04^{\prime} 18^{\prime \prime}$ & $132(433)$ & Piedmont and Blue Ridge \\
\hline Anderson County & 343714082285600 AND-326 & $34^{\circ} 37^{\prime} 14^{\prime \prime}$ & $82^{\circ} 28^{\prime} 56^{\prime \prime}$ & $121(398)$ & crystalline-rock aquifer \\
\hline McCormick County & 335336082214600 MCK-52 & $33^{\circ} 53^{\prime} 36^{\prime \prime}$ & $82^{\circ} 21^{\prime} 46^{\prime \prime}$ & $62(202)$ & \\
\hline Marlboro County & 343715079411500 MLB-112 & $34^{\circ} 37^{\prime} 35^{\prime \prime}$ & $79^{\circ} 41^{\prime} 22^{\prime \prime}$ & $105(345)$ & Southeastern Coastal Plain aquifer \\
\hline Florence County & 340806079563100 FLO-85 & $34^{\circ} 08^{\prime} 06^{\prime \prime}$ & $79^{\circ} 56^{\prime} 31^{\prime \prime}$ & $167(549)$ & \\
\hline Sumter County & 335602080204800 SU-9 & $33^{\circ} 56^{\prime} 02^{\prime \prime}$ & $80^{\circ} 20^{\prime} 48^{\prime \prime}$ & $191(625)$ & \\
\hline Horry County & 335115079033500 HO-307 & $33^{\circ} 50^{\prime} 58^{\prime \prime}$ & $79^{\circ} 03^{\prime} 27^{\prime \prime}$ & $134(438)$ & \\
\hline Williamsburg County & $334410079310200 \mathrm{WL}-76$ & $33^{\circ} 43^{\prime} 50^{\prime \prime}$ & $79^{\circ} 31^{\prime} 20^{\prime \prime}$ & $78(257)$ & \\
\hline
\end{tabular}

\begin{tabular}{|c|c|c|c|c|c|}
\hline Name & Record length & Mean $[\mathrm{m}(\mathrm{ft})]$ & Standard deviation $[\mathrm{m}(\mathrm{ft})]$ & $\mathrm{CV}$ & Periodicity \\
\hline Oconee County & 1994-2012 & $9.00(29.52)$ & $0.38(1.26)$ & 0.04 & - \\
\hline Anderson County & 1994-2009 & $0.98(3.20)$ & $0.12(0.38)$ & 0.12 & $1 / 24,1 / 12$ \\
\hline McCormick County & 1993-2014 & $11.02(36.14)$ & $0.52(1.69)$ & 0.05 & $1 / 24,1 / 12$ \\
\hline Marlboro County & $1980-2005$ & $1.11(3.65)$ & $0.20(0.66)$ & 0.18 & $1 / 12$ \\
\hline Florence County & 1981-1992 & $6.07(19.90)$ & $0.53(1.73)$ & 0.09 & $1 / 36,1 / 24,1 / 12$ \\
\hline Sumter County & 1982-1992 & $18.90(62.00)$ & $1.00(3.27)$ & 0.05 & $1 / 36,1 / 24,1 / 12$ \\
\hline Horry County & 1974-1988 & $10.01(32.84)$ & $3.9(12.83)$ & 0.39 & - \\
\hline Williamsburg County & 1982-1992 & $11.80(38.71)$ & $0.54(1.77)$ & 0.05 & $1 / 36,1 / 24,1 / 12$ \\
\hline
\end{tabular}

For the configurational entropy approach, which is equivalent to the relative entropy without a prior assumption, the cepstrum $e_{q}$ in Eq. (9) equals 0 . The prior autocepstrum $e_{q}$ can be estimated from the observed periodicity of monthly groundwater level, while the

Table 1. Summary of Groundwater Stations

Table 2. Statistics of Groundwater Levels of Each Station

Note: $\mathrm{CV}=$ standard deviation $/$ mean 


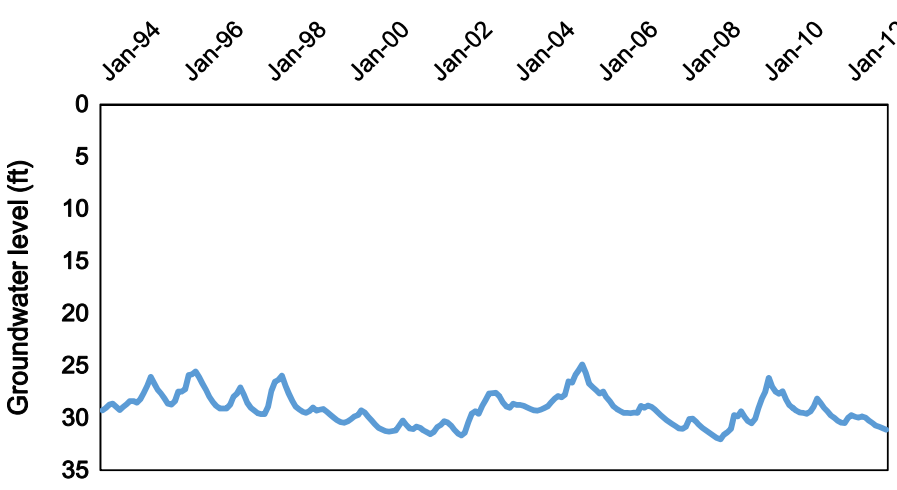

(a)

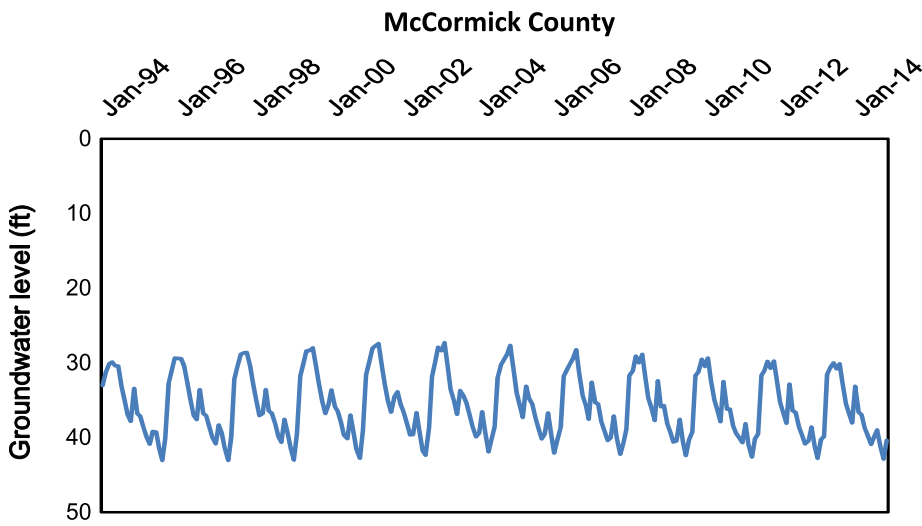

(c)

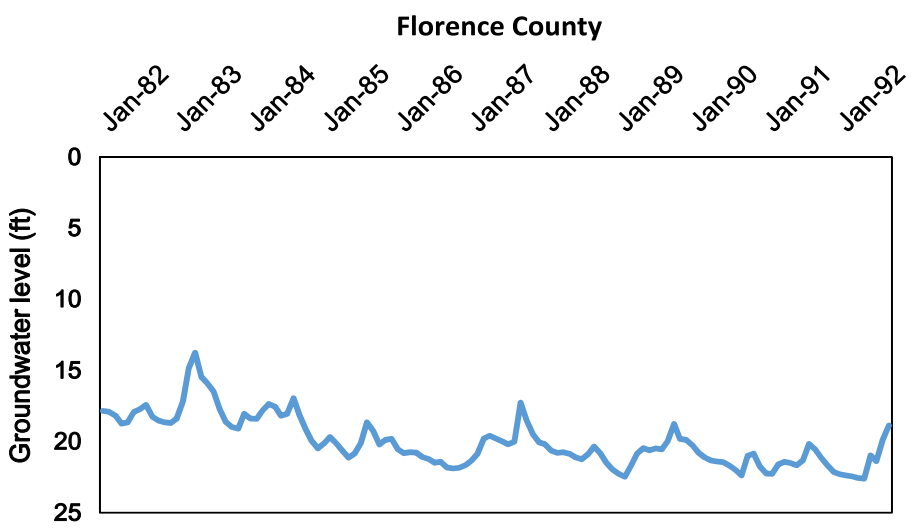

(e)

Horry County
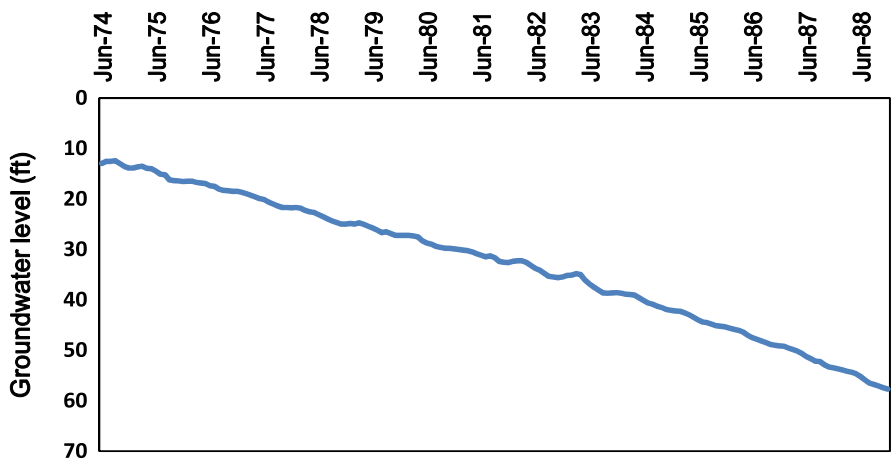

(g)

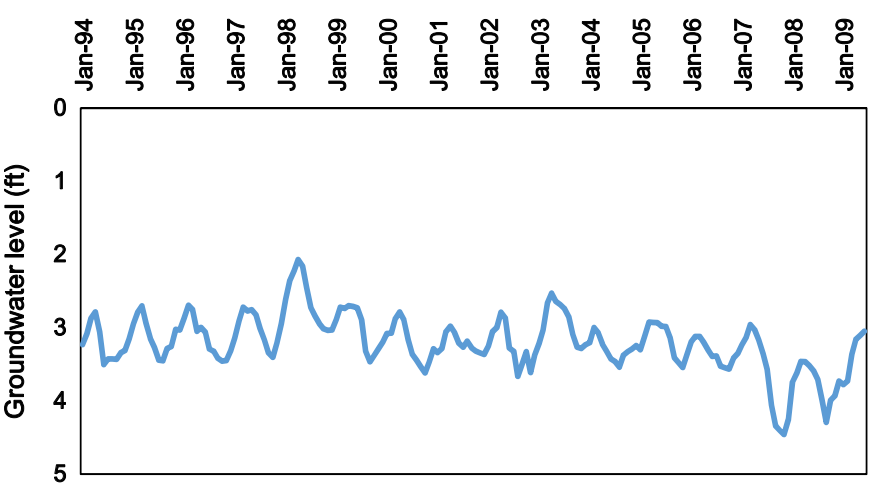

(b)

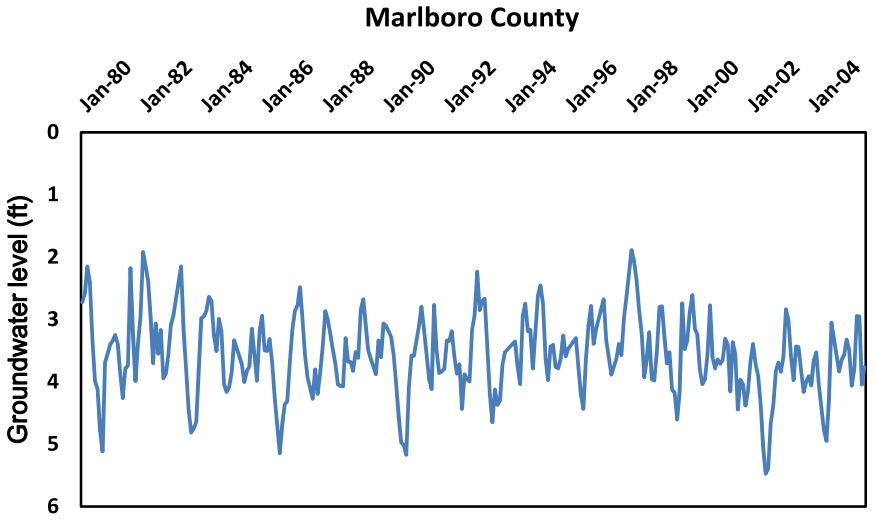

(d)

Sumter County

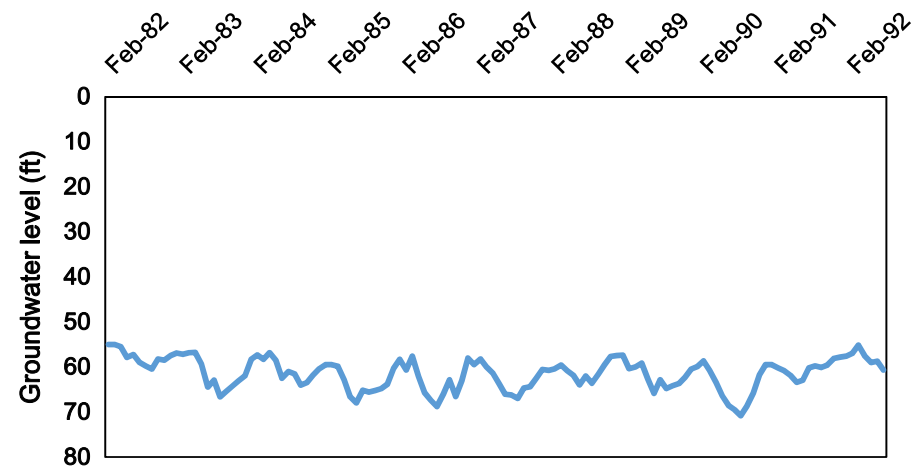

(f)

Williamsburg County

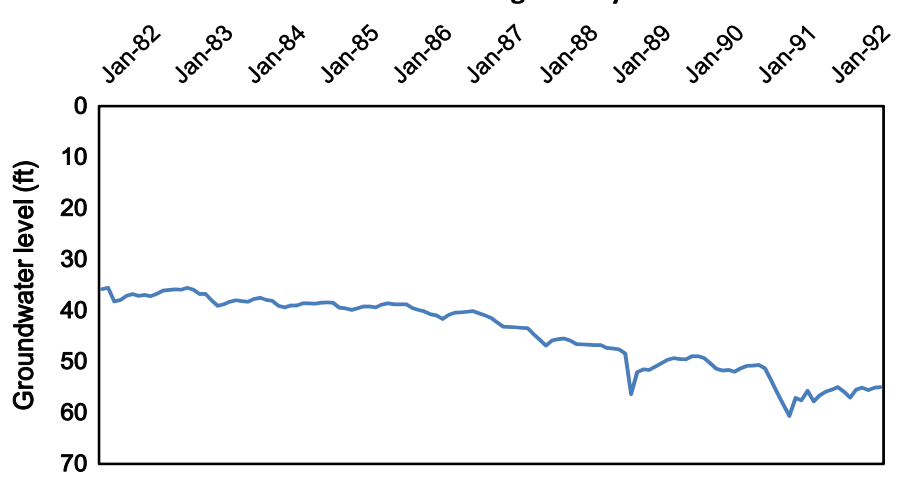

(h)

Fig. 1. Time series of groundwater level: (a) Oconee County; (b) Anderson County; (c) McCormick County; (d) Marlboro County; (e) Florence County; (f) Sumter County; (g) Horry County; (h) Williamsburg County 
Table 3. Results of Mann-Kendall Test and Trend of Monthly Groundwater Level Series

\begin{tabular}{lccc}
\hline Name & $\mathrm{H}$ & $p$-Value & Trend \\
\hline Oconee County & 1 & $<0.001$ & 0.007 \\
Anderson County & 1 & $<0.001$ & 0.003 \\
McCormick County & 1 & 0.03 & 0.007 \\
Marlboro County & 1 & 0.0188 & 0.001 \\
Florence County & 1 & $<0.001$ & 0.034 \\
Sumter County & 0 & 0.226 & 0.012 \\
Horry County & 1 & $<0.001$ & 0.253 \\
Williamsburg County & 1 & $<0.001$ & 0.1775 \\
\hline
\end{tabular}

Table 4. Results of Mann-Kendall Test and Trend of Annual Groundwater Level Series

\begin{tabular}{lccc}
\hline Name & $\mathrm{H}$ & $p$-Value & Trend \\
\hline Oconee County & 0 & 0.124 & 0.077 \\
Anderson County & 1 & 0.006 & 0.036 \\
McCormick County & 1 & $<0.001$ & 0.580 \\
Marlboro County & 0 & 0.2517 & 0.001 \\
Florence County & 1 & 0.005 & 0.373 \\
Sumter County & 0 & 0.640 & 0.087 \\
Horry County & 1 & $<0.001$ & 2.997 \\
Williamsburg County & 1 & $<0.001$ & 1.9719 \\
\hline
\end{tabular}

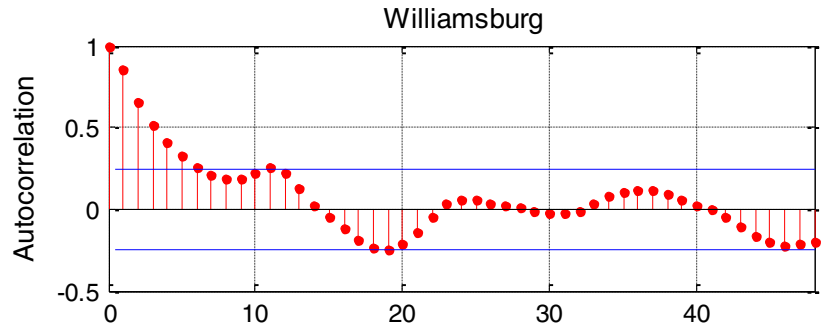

(a)

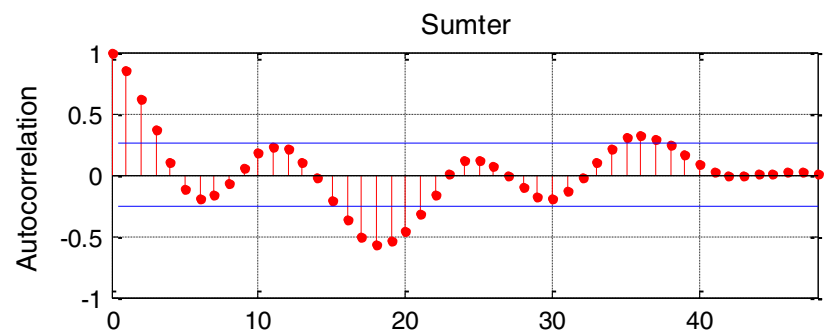

(c)

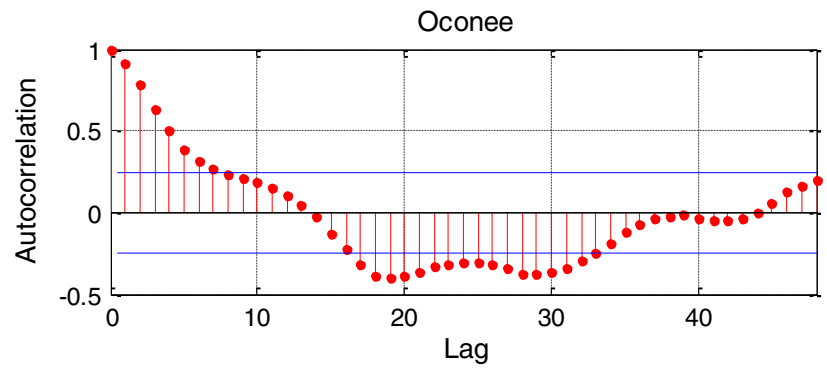

(e) posterior autocepstrum $e_{p}$ can be estimated from the following recursive function introduced by Nadeu (1992) as

$$
e_{p}(n)=2\left[\rho(n)-\sum_{k=1}^{n-1} \frac{k}{n} e_{p}(k) \rho(n-k)\right], \quad n>0
$$

\section{Forecasting}

As shown in Eq. (6), BESA is related to a linear process, as the spectral density of a linear process is in the form of polynomials (Box and Jenkins 1970). Thus, using BESA, the groundwater level can be forecasted by a linear combination of previous values weighted by the coefficients solved from Levinson-Burg algorithm, which becomes

$$
\hat{y}_{t}=a_{1} y_{t-1}+a_{2} y_{t-2}+\cdots+a_{m} y_{t-m}
$$

When using CESA or RESA, groundwater level was forecasted with cepstrum analysis, as shown by Cui and Singh $(2015,2016)$

Therefore, groundwater level becomes

$$
\hat{y}_{t}=\frac{1}{4} e_{p}(t)+\frac{1}{2} \sum_{j=1}^{m} \frac{k}{t} e_{r q}(j) y(t-j)
$$

For CESA, as no prior is given, $e_{p}$ is 0 .

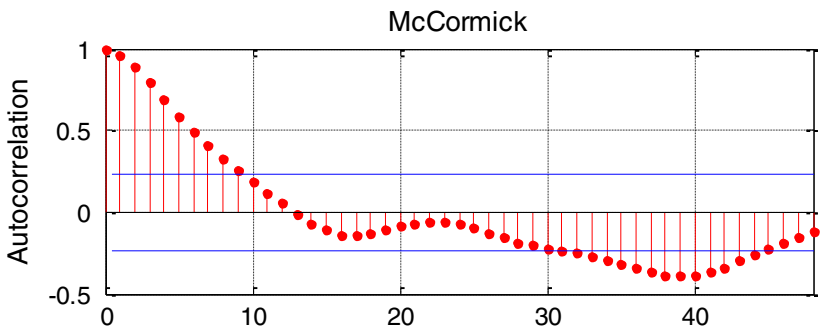

(b)

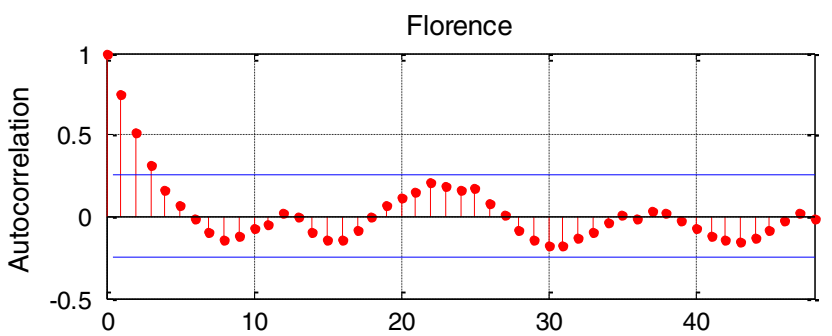

(d)

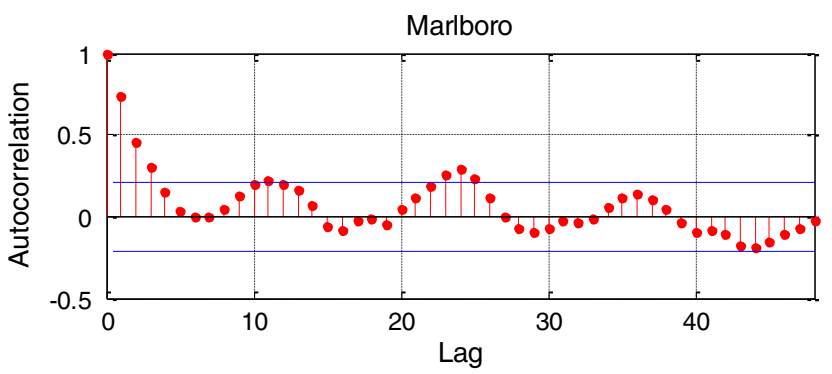

(f)

Fig. 2. Plot of autocorrelation function with $90 \%$ confidence intervals of (a) Williamsburg County; (b) McCormick County; (c) Sumter County; (d) Florence County; (e) Oconee County; (f) Marlboro County 
The goodness of spectral analysis-based forecasted groundwater level was evaluated by the root-mean square (RMSE), coefficient of determination $\left(R^{2}\right)$, and Nash-Sutcliffe efficiency (NSE).

\section{Data}

Monthly groundwater data are collected by South Carolina Department of Natural Resources in cooperation with the USGS for waterresources assessment and management. The groundwater level was estimated as the depth of water level from the land surface. As indicated in Table 1, eight stations were chosen from different locations to evaluate the proposed methods. The depths of wells varied from $61 \mathrm{~m}(200 \mathrm{ft})$ to more than $183 \mathrm{~m}(600 \mathrm{ft})$ below the land's surface. Furthermore, the wells of Oconee, Anderson, and McCormick Counties have been constructed in the Piedmont and Blue Ridge crystalline-rock aquifers, and others in the Southeastern Coastal Plain aquifer system.
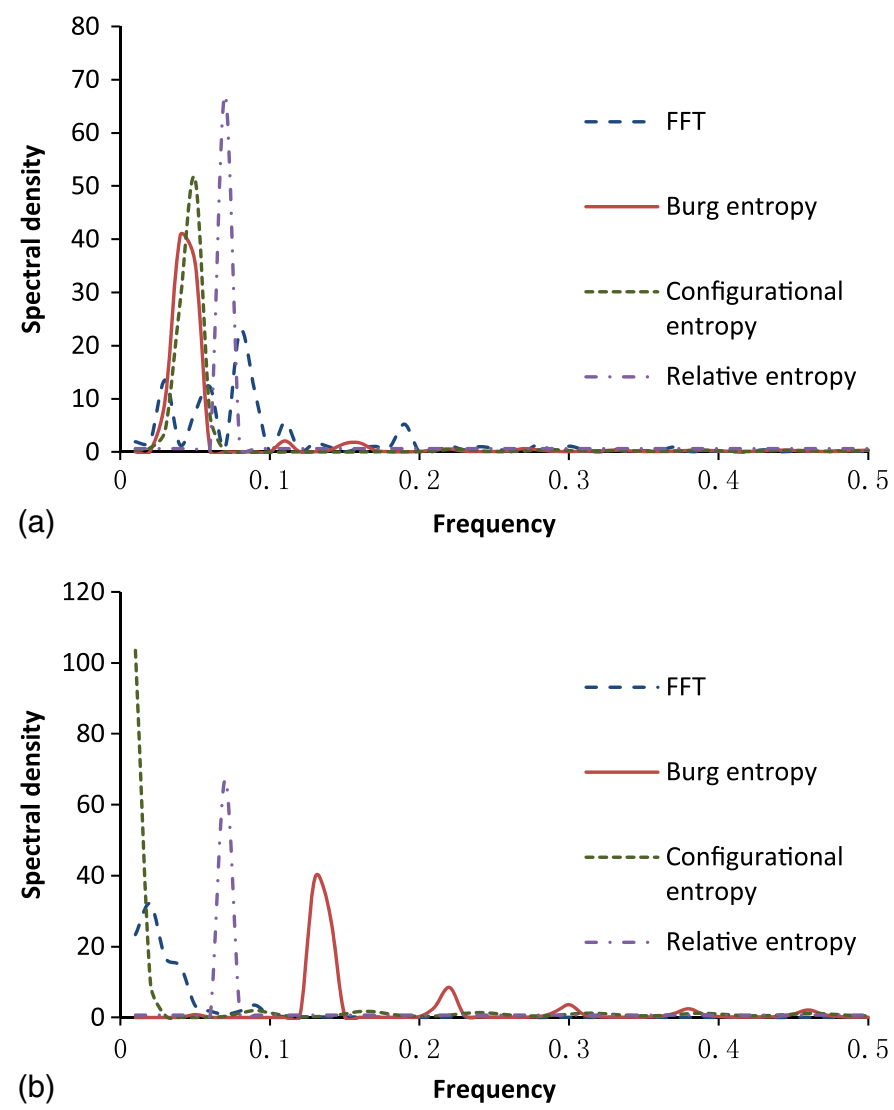

Fig. 3. Estimated spectral density of (a) Williamsburg County; (b) Oconee County

Table 5. Itakura-Saito Distance of Estimated Spectral Density

\begin{tabular}{lrrr}
\hline Name & BESA & CESA & RESA \\
\hline Oconee County & 86.62 & 41.79 & 10.48 \\
Anderson County & 83.20 & 57.34 & 20.11 \\
McCormick County & 95.79 & 8.04 & 4.47 \\
Marlboro County & 93.37 & 10.65 & 8.77 \\
Florence County & 57.88 & 32.44 & 15.23 \\
Sumter County & 74.21 & 35.23 & 7.39 \\
Horry County & 69.31 & 33.59 & 13.55 \\
Williamsburg County & 59.73 & 74.47 & 12.68 \\
\hline
\end{tabular}

The statistics of groundwater-level series are given in Table 2, where at least 10 years of data were collected at each station. It was found that the pattern of groundwater level varied dramatically. The mean of groundwater level varied from 1.0 to $19 \mathrm{~m}(3.20$ to $62.00 \mathrm{ft}$ ), while the coefficient of variation $(\mathrm{CV})$ of groundwater level was around 0.12 . The highest value of $\mathrm{CV}$ was observed in the Horry County as 0.39 , more than two times than others. As shown in the plot of monthly groundwater level in Fig. 1, the groundwater level in the Horry County dropped significantly from 3.95 to 17.57 $\mathrm{m}(12.96$ to $57.64 \mathrm{ft})$ within 15 years of duration, while that of other counties remained equal or dropped within $6 \mathrm{~m}(20 \mathrm{ft})$. Different periodic patterns were noticed for different stations. A significant 24-month periodic pattern in groundwater level was found in McCormick County, and a nonsinusoidal periodic pattern (12 month) was found in Anderson County, Florence County, and Sumter County. However, for stations like Horry County or Oconee County, no significant periodicity was observed.

Significant trends can be observed from monthly groundwater at almost all stations in Fig. 1. Thus, the Mann-Kendall nonparametric test was applied to identify the trend in groundwater series. As given in Table 3, monthly groundwater level at all stations except that in Sumter County had significant trends with very small $p$-values $(\alpha=0.05)$, where the $p$-values were all less than 0.03 . The estimated trends are listed in the table as well. A positive trend responded to the decline in groundwater level, which suggested that groundwater levels at all stations were found to decrease over the years. Groundwater levels in Horry and Williamsburg Counties dropped the fastest among them. On the other hand, applying the Mann-Kendall test to annual groundwater level showed that groundwater in Oconee and Anderson Counties did not contain significant trends, in addition to Sumter County, as indicated in Table 4.

The autocorrelation of the groundwater time series is plotted in Fig. 2, with $90 \%$ confidence intervals. As shown in the figure, at

Table 6. Errors from Simulating Monthly Groundwater Level

\begin{tabular}{lcccc}
\hline Station & Method & RMSE $[\mathrm{m}(\mathrm{ft})]$ & $R^{2}$ & NSE \\
\hline Oconee County & BESA & $0.069(0.228)$ & 0.720 & 0.715 \\
& CESA & $0.186(0.061)$ & 0.794 & 0.750 \\
Anderson County & RESA & $0.018(0.058)$ & 0.795 & 0.754 \\
& BESA & $0.025(0.082)$ & 0.897 & 0.866 \\
& CESA & $0.018(0.059)$ & 0.899 & 0.874 \\
McCormick County & RESA & $0.007(0.025)$ & 0.903 & 0.889 \\
& BESA & $0.682(2.238)$ & 0.719 & 0.618 \\
Marlboro County & CESA & $1.064(3.492)$ & 0.627 & 0.576 \\
& RESA & $1.060(3.479)$ & 0.722 & 0.603 \\
Florence County & BESA & $0.169(0.556)$ & 0.704 & 0.755 \\
& CESA & $0.252(0.827)$ & 0.653 & 0.674 \\
& RESA & $0.235(0.770)$ & 0.693 & 0.715 \\
Sumter County & BESA & $0.039(0.129)$ & 0.953 & 0.847 \\
& CESA & $0.024(0.080)$ & 0.997 & 0.932 \\
& RESA & $0.020(0.067)$ & 0.998 & 0.939 \\
Williamsburg County & BESA & $1.629(5.313)$ & 0.745 & 0.686 \\
& CESA & $1.608(5.276)$ & 0.760 & 0.732 \\
Horry County & RESA & $1.608(5.277)$ & 0.762 & 0.728 \\
& BESA & $0.095(0.313)$ & 0.945 & 0.886 \\
& CESA & $1.034(3.394)$ & 0.761 & 0.847 \\
& RESA & $1.146(3.760)$ & 0.707 & 0.791 \\
\hline \multirow{5}{*}{ RESA } & $0.084(0.276)$ & 0.960 & 0.932 \\
& & $0.084(0.277)$ & 0.962 & 0.928 \\
& & & &
\end{tabular}


least the first three lags of autocorrelation were beyond the bounds, and thus were significant. Two types of autocorrelation patterns were found in general. For Williamsburg, Sumter, Florence, and Marlboro Counties, the autocorrelation fluctuated around the confidence intervals with a 12-month periodicity. In contrast, the autocorrelation in the McCormick and Oconee Counties monotonically decreased from the first lag and the periodicity was weak.

\section{Results and Discussion}

\section{Estimation of Spectral Density}

The spectral density was obtained by maximizing or minimizing entropy, subject to autocorrelations as constraints. Thus, based on the pattern of autocorrelation, the obtained spectral density generally fell into two categories. For the autocorrelation with significant periodicity, the corresponding spectral density consisted of several peaks, while for monotonically decreasing autocorrelation, the spectral peaks were not significant. As shown in Fig. 3, the spectral density of Williamsburg belonged to the first category, and possessed spectral peaks at frequencies of 1/36, 1/16, and 1/12. The largest peak was found at $1 / 12$ frequency, which suggested that monthly groundwater levels contained strong yearly periodicity. In contrast, the spectral density of groundwater level in Oconee County did not reveal such patterns. No significant peak was observed from spectral density obtained from Fast Fourier transform (FFT), while it decreased from small frequencies to large frequencies.

In Figs. 3( $a$ and b), BESA produced the same kind of spectral density, which had a unique significant peak. However, the peak neither fitted the one from FFT nor was located at any of the periodicities, which was at 1/12 frequency for Williamsburg County, and $1 / 8$ frequency for Oconee County. CESA performed differently in Figs. 3(a and b). For Williamsburg County, the spectral density obtained from CESA was similar to that of BESA with a unique peak at $1 / 8$ frequency, while for Oconee County, the spectral density obtained from CESA monotonically decreased for small frequencies. With prior spectral density assuming a peak at 1/12 frequency, RESA produced very similar spectral densities for the two cases, which had a unique peak at 1/12 frequency. In general, it was hard to judge from the figure which entropy-based analysis provided the best estimate. As given in Table 5, the Itakura-Saito (I-S) distance value, which measures the perceptual difference between an original spectrum and its estimate, was the smallest using RESA, followed by CESA and BESA, respectively.

\section{Forecasting of Groundwater Level}

Table 6 summarizes measures of goodness-of-fit of forecasted monthly groundwater level, which showed that the three methods provided similar results. The $R^{2}$ was higher than 0.62 and the NSE was higher than 0.57 in all cases. The average values of NSE for BESA, CESA, and RESA were 0.69, 0.70, and 0.70, respectively. Although Sumter County was observed to have the highest RMSE values, because its mean level fluctuated around $19 \mathrm{~m}(62 \mathrm{ft})$, its errors were still within $8 \%$.

Fig. 4 demonstrates that the groundwater levels forecasted by the three methods did not show significant differences either. It is interesting to find that the three methods performed in much the
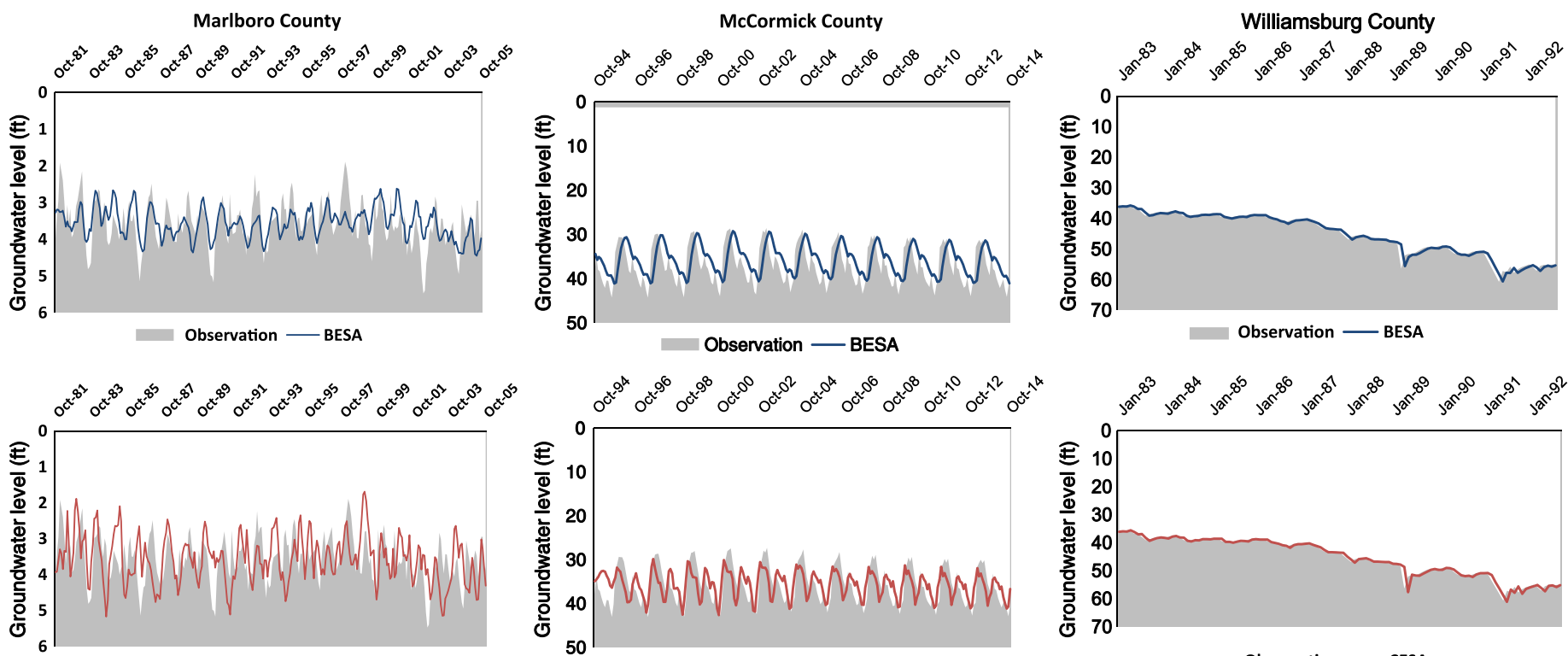

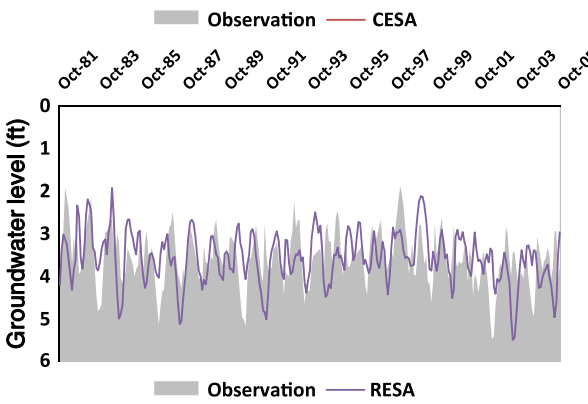

(a)

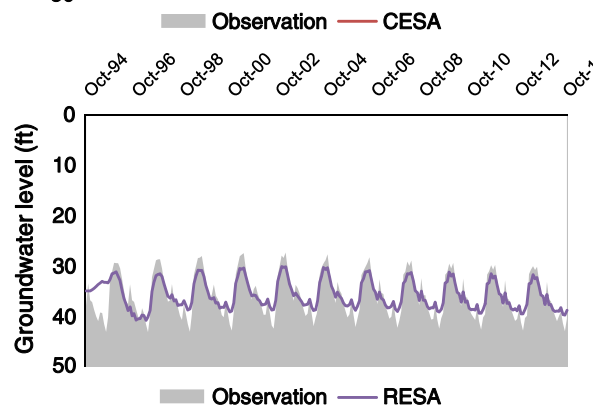

(b)

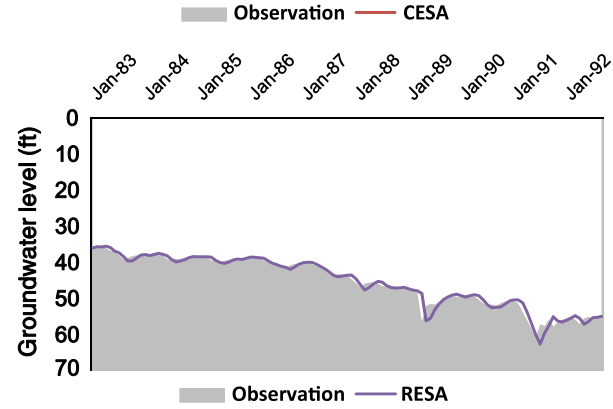

(c)

Fig. 4. Simulation of monthly groundwater level in (a) Marlboro County; (b) McCormick County; (c) Williamsburg County 
same way in forecasting groundwater in Williamsburg County, where groundwater monotonically decreased. The largest difference exhibited by the three entropy methods was in forecasting groundwater in Marlboro County, where the groundwater level was most random in all cases. The forecasted groundwater fluctuated with frequency similar to that of observed values; however, none of them exactly followed the observed values. It is seen from Fig. 4 that BESA underestimated groundwater levels for 1992-1998, but the overall trend was similar to that of observed values. However, groundwater estimated by CESA and RESA had a range similar to that of observed values, but the timings of peak were shifted. Thus, in this case, $R^{2}$ for BESA, CESA, and RESA was only 0.704 , 0.653 , and 0.693 , respectively. The three methods behaved differently in forecasting groundwater levels in McCormick County. RESA seemed to overestimate the groundwater level during the low-flow season, while the groundwater level forecasted by BESA was one step later than that of the other methods and the observed

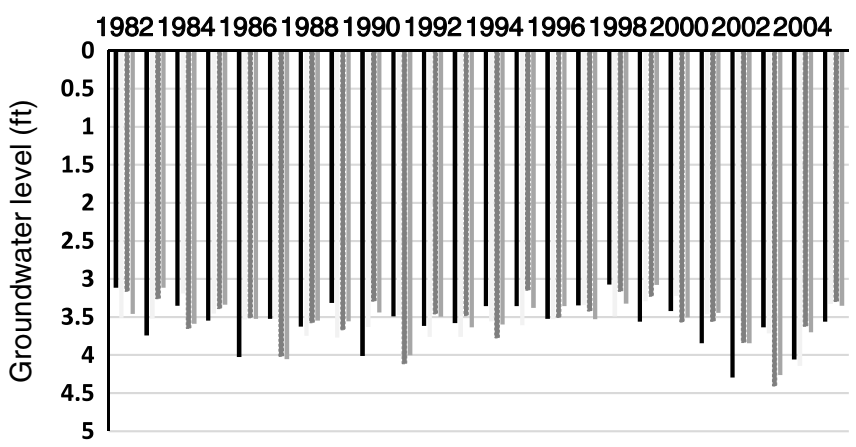

(a)

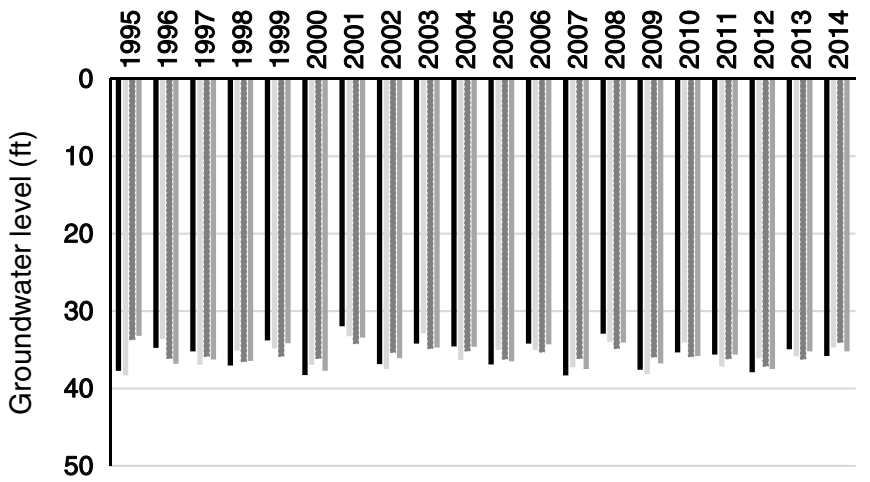

(b)

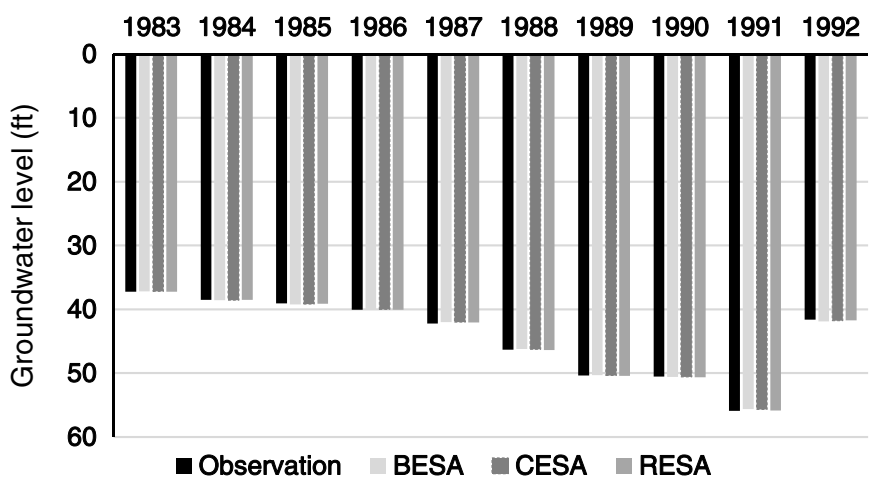

(c)

Fig. 5. Simulation of annual groundwater level in (a) Marlboro County; (b) McCormick County; (c) Williamsburg County values, which may be caused by the shifted peak from the estimated spectral density. The groundwater level forecasted by CESA seemed to exhibit 1/12 frequency; as a result, the forecasted peak occurred every year. But BESA and RESA seemed to recognize the $1 / 24$ periodicity and forecasted two peaks of different sizes. In this case, $R^{2}$ for BESA, CESA, and RESA was only $0.719,0.622$, and 0.727 , respectively.

In addition, forecasted annual groundwater levels were plotted as shown in Fig. 5. As depicted in Table 2, as not all stations had data covering more than 10 years, only groundwater data from Marlboro, McCormick, and Williamsburg Counties were used for forecasting. As shown in Fig. 5, the result was similar to forecasted monthly groundwater level. For Williamsburg County, the three methods showed similar accuracy, but had the largest divergence in Marlboro County. The average $R^{2}$ obtained by the three methods was $0.759,0.763$, and 0.765 , respectively.

\section{Conclusion}

Three entropy spectral analysis methods using Burg entropy, configurational entropy, and relative entropy were developed for groundwater level forecasting. With entropy defined in the frequency domain, temporal uncertainties can be captured. Monthly groundwater time series obtained from South Carolina were used to verify the proposed methods. Both monthly and annual groundwater levels show significant decreasing trends at almost all stations. Besides, monthly groundwater possesses different characteristics; for some wells, a clear 12-month periodicity is observed, while other wells do not exhibit any pattern at all. For forecasting groundwater levels, all three methods fit observations well with reasonable accuracy. For groundwater with a strong declining trend, the agreement among the three methods is highest. But when groundwater level fluctuates more frequently, the methods behave differently. BESA may forecast groundwater with one step early or late, CESA may exhibit 24-month to 12-month periodicity, and RESA may overestimate groundwater level in low-level seasons.

As introduced in this paper, entropy spectral analysis provides an alternative approach to provide a long-term perspective of groundwater levels, considering both trends and fluctuations. Although forecasting groundwater time series using entropy spectral analyses yields reasonable accuracy, the entropy spectral analysis has limitations in application. The three proposed spectral analyses require historical data for initial analysis and may not be applicable for conditions where no or little observed data are available. Furthermore, they also require data under the same conditions and may not be applicable to transient conditions.

\section{Acknowledgments}

This research is supported by the Key Research Program of the Chinese Academy of Sciences (ZDRW-ZS-2016-6-4).

\section{Notation}

The following symbols are used in this paper: $a=$ linear predictor;

$c(n)=$ autocepstrum;

$e(n)=$ cepstrum;

$f=$ continues frequency;

$H(f)=$ entropy;

$N=$ total number of observation;

$n=$ time lag; 
$p(f)=$ (posterior) spectral density;

$q(f)=$ prior spectral density;

$t=$ time variable;

$W=$ Nyquist foldover frequency;

$y_{t}=$ groundwater level at time $t$;

$\hat{y}_{t}=$ modeled groundwater level at time $t$;

$\Delta t=$ sampling period;

$\lambda_{n}=$ Lagrange multipliers; and

$\rho_{n}=$ autocorrelation for lag $n$.

\section{References}

Barbe, D. E., Cruise, J. F., and Singh, V. P. (1994). "Derivation of a distribution for the piezometric head in groundwater flow using entropy." Stochastic and statistical methods in hydrology and environmental engineering, K. W. Hipel, ed., Kluwer Academic Publishers, Dordrecht, Netherlands.

Box, G. E. P., and Jenkins, G. M. (1970). "Time series analysis: Forecasting and control." Holden-Day series in time series analysis, Holden-Day, San Francisco, 553.

Burg, J. P. (1967). "Maximum entropy spectral analysis." Proc., 37th Meeting of Society Exploration Geophysics, Oklahoma City, 34-41.

Burg, J. P. (1975). "Maximum entropy spectral analysis." Ph.D. thesis, Stanford Univ., Standford, CA, 123.

Cui, H., and Singh, V. P. (2015). "Configurational entropy theory for streamflow forecasting." J. Hydrol., 521(0), 1-17.

Cui, H., and Singh, V. P. (2016). "Minimum relative entropy theory for streamflow forecasting with frequency as a random variable." Stoch. Env. Res. Risk A, 30(6), 1545-1563.

Frieden, B. R. (1972). "Restoring with maximum likelihood and maximum entropy." J. Opt. Soc. Am., 62(4), 511-518.

Gull, S. F., and Daniell, G. J. (1978). "Image-reconstruction from incomplete and noisy data." Nature, 272(5655), 686-690.

Jaynes, E. T. (1957a). "Information theory and statistical mechanics.1." Phys Rev, 106(4), 620-630.

Jaynes, E. T. (1957b). "Information theory and statistical mechanics. 2." Phys Rev, 108(2), 171-190.

Krstanovic, P. F., and Singh, V. P. (1991a). "A univariate model for long-term streamflow forecasting. 1: Development." Stoch. Hydrol. Hydraul., 5(3), 173-188.

Krstanovic, P. F., and Singh, V. P. (1991b). "A univariate model for longterm streamflow forecasting. 2: Application." Stoch. Hydrol. Hydraul., 5(3), 189-205.
Liefhebber, F., and Boekee, D. E. (1987). "Minimum information spectralanalysis." Signal Process., 12(3), 243-255.

Mogheir, Y., de Lima, J. L. M. P., and Singh, V. P. (2004). "Characterizing the spatial variability of groundwater quality using the entropy theory. II: Case study from Gaza Strip." Hydrol. Process., 18(13), 2579-2590.

Mogheir, Y., de Lima, J. L. M. P., and Singh, V. P. (2009). "Entropy and multi-objective based approach for groundwater quality monitoring network assessment and redesign." Water Resour. Manage., 23(8), $1603-1620$.

Mogheir, Y., Singh, V. P., and de Lima, J. L. M. P. (2006). "Spatial assessment and redesign of a groundwater quality monitoring network using entropy theory, Gaza Strip, Palestine.” Hydrogeol. J., 14(5), 700-712.

Nadeu, C. (1992). "Finite length cepstrum modeling —A simple spectrum estimation technique." Signal Process., 26(1), 49-59.

Papademetriou, R. C. (1998). "Experimental comparison of two information-theoretic spectral estimators." Signal Processing Proc., 1998, ICSP '98, 4th Int. Conf., Beijing, 141-144.

Shore, J. E. (1979). Minimum cross-entropy spectral analysis, Naval Research Laboratory, Washington, DC.

Shore, J. E. (1981). "Minimum cross-entropy spectral-analysis." IEEE Trans. Acoust. Speech, 29(2), 230-237.

Singh, V., and Cui, H. (2015). "Entropy theory for streamflow forecasting." Environ. Process., 2(3), 1-12.

Singh, V. P. (1997). "The use of entropy in hydrology and water resources." Hydrol. Process., 11(6), 587-626.

Singh, V. P. (2011). "Hydrologic synthesis using entropy theory: Review.” J. Hydrol Eng., 10.1061/(ASCE)HE.1943-5584.0000332, 421-433.

Singh, V. P., Jain, S. K., and Tyagi, A. (2007). "Entropy theory and its applications in risk analysis." Risk and reliability analysis, 356-391.

Tzannes, M. A., Politis, D., and Tzannes, N. S. (1985). "A general method of minimum cross-entropy spectral estimation." IEEE T. Acoust. Speech, 33(3), 748-752.

Woodbury, A. D., and Ulrych, T. J. (1993). "Minimum relative entropy-Forward probabilistic modeling." Water Resour. Res., 29(8), 2847-2860.

Woodbury, A. D., and Ulrych, T. J. (1996). "Minimum relative entropy inversion: Theory and application to recovering the release history of a groundwater contaminant." Water Resour. Res, 32(9), 2671-2681.

Woodbury, A. D., and Ulrych, T. J. (1998). "Minimum relative entropy and probabilistic inversion in groundwater hydrology." Stoch. Hydrol. Hydraul., 12(5), 317-358. 